\title{
Estado educador: uma nova pedagogia da hegemonia nas Reservas Extrativistas
}

\section{Cláudia Conceição Cunha}

Instituto Chico Mendes de Conservação da Biodiversidade (ICMBio)

\author{
Carlos Frederico B. Loureiro \\ Universidade Federal do Rio de Janeiro (UFRJ)
}

\section{Estado educador: uma nova pedagogia da hegemonia nas Reservas Extrativistas}

Resumo: Este artigo analisa o papel desempenhado por um projeto de cooperação internacional (Projeto Resex) na implementação das Reservas Extrativistas na década de 1990. Através da análise dos documentos e relatórios referentes à negociação e execução da primeira fase do Projeto, no período de 1995-1999, demonstra-se a contraposição dos princípios contidos nos sujeitos coletivos que originaram as Reservas Extrativistas e aqueles produzidos, transmitidos e difundidos através do Projeto Resex. Discute-se a presença do Estado, em uma pedagogia da hegemonia, operando na desconstrução das conquistas objetivadas pelos seringueiros nas décadas de 1970-1980, e utilizando, para isso, o Projeto Resex como um espaço pedagógico privilegiado.

Palavras-chave: Reserva Extrativista. Políticas ambientais. Amazônia. Pedagogia da hegemonia. Estado educador.

\section{Educator State: a New Pedagogy of Hegemony in Extractive Reserves}

Abstract: This article analyzes the role performed by an international cooperation project (Projeto Resex) in the implementation of Extractive Reserves in the 1990s. Through the analysis of documents and reports referring to the negotiation and execution of the first phase of the Project in 1995-1999, the paper demonstrates the conflicting principles held by the collective subjects that participated in the formation of the Extractive Reserves and those produced, transmitted and promoted through the Projeto Resex. The presence of the state is discussed, found in a pedagogy of hegemony, operating in the deconstruction of the conquests sought by the rubber tappers in the 1970s and 1980s, and using Project Resex as a special pedagogic space.

Keywords: Extractive Reserve. Environmental Policy. Amazon. Pedagogy of hegemony. Educator State. 


\section{Introdução}

Em 1985, ao realizar seu I Encontro Nacional, em Brasília, os seringueiros tornaram pública uma proposta que lhes daria a garantia da terra e seu usufruto, as Reservas Extrativistas (Resex). Naquele momento, os seringueiros tentavam, baseados nas Reservas Indígenas, uma formulação que lhes assegurasse a posse da terra (em apropriação coletiva) e a forma de utilização (segundo métodos tradicionais). As Resex surgem como uma proposta de mudança na estrutura territorial e socioeconômica da região, em que o "direito de ficar" se sobrepõe ao "direito de ir e vir" dominante na sociedade capitalista e explicitado pelo direito de compra e venda de propriedades (PORTO-GONÇALVES, 2000).

Primeiramente, institucionalizadas no âmbito da Política Agrária, na forma de Projetos de Assentamento Extrativistas, as Reservas Extrativistas foram criadas como Unidades de Conservação da Natureza através do Decreto n. 98.897, de 30 de janeiro de 1990 (BRASIL, 1990). A conhecida "reforma agrária dos seringueiros" foi vinculada à política ambiental brasileira em função da aproximação com o movimento ambientalista e de uma conjuntura política favorável nesse campo.

Na década de 90, verificou-se um aumento progressivo no número de Resex criadas na Amazônia, assim como sua expansão para outros biomas brasileiros. Todavia, não houve correspondência no aporte de recursos públicos para a gestão das mesmas, a não ser aqueles advindos de projetos de cooperação internacional. Alguns estudos relatam o pouco atendimento dessas políticas a seus objetivos iniciais, assim como retratam uma nova arquitetura de interlocução dos seringueiros em relação às instâncias de decisão na construção e execução das políticas públicas (AZEVEDO, 2003; LÉNA, 2002; CUNHA, 2010).

Este quadro nos remete à necessidade de analisar o processo de implementação das Resex em seu contexto histórico, as correlações de forças existentes e os arranjos entre os grupos que compõem os diversos interesses envolvidos, compreendendo o papel assumido pelos diferentes atores sociais. Suas determinações e limitações no cenário histórico e as possíveis ressignificações de um projeto, que, forjado na luta de classes, representou uma tensão entre um modelo de sociedade hegemônico (capitalista) e um ideário emancipatório das classes subalternas.

Para efeito dessa análise, utilizaremos as reflexões de Neves e Sant' anna (2005, p. 27) que, ao se apropriarem do conceito gramsciano de hegemonia, discutem o papel do Estado na construção do consenso, quando "na condição de um Estado educador, o Estado capitalista desenvolveu e desenvolve uma pedagogia da hegemonia, com ações concretas na aparelhagem estatal e na sociedade civil." Os auto- res apontam como traços definidores desse momento do Estado neoliberal: redefinição da participação caracterizada por soluções individuais, desmantelamento e/ou refuncionalização dos aparelhos privados de hegemonia da classe trabalhadora, estímulo estatal à expansão de grupos de interesse não diretamente ligados às relações de trabalho, e, por último, ação orgânica de entidades internacionais, em especial o Fundo Monetário Internacional e o Banco Mundial.

Neste contexto, o Projeto Reserva Extrativista (Projeto Resex), administrado pelo Banco Mundial e parte integrante do Programa Piloto para Proteção de Florestas Tropicais do Brasil, consistiu em um importante espaço para discussão da operacionalidade da pedagogia da hegemonia em relação às conquistas do Movimento Seringueiro. Por representar a maior soma de recursos aplicados nas reservas em sua primeira década de existência, o impacto do Projeto Resex teve alta correlação com a sua capacidade de financiar e disseminar práticas, conceitos e estratégias, contribuindo na definição das normas que orientariam os futuros processos de criação e gestão das Reservas Extrativistas. Assim, o Projeto pode ser melhor entendido como um laboratório em que experiências eram gestadas e difundidas para as outras Reservas Extrativistas. Cabe-nos compreender como novas relações sociais foram arquitetadas e sua implicação para as conquistas dos seringueiros.

Para esta pesquisa, foram analisados documentos e relatórios referentes à negociação e à execução da primeira fase do Projeto Reservas Extrativistas (Projeto Resex/PPG-7), no período de 1995-1999. O objetivo foi examinar criticamente o papel desempenhado pelo Projeto Resex na implementação das referidas Reservas na década de 1990, bem como sua participação como agente pedagógico em confronto às anteriores conquistas dos seringueiros nas décadas de 1970 e 1980, por representar, para nós, um ator importante e estratégico na materialização da chamada Pedagogia da Hegemonia.

\section{Programa piloto para as florestas tropicais do Brasil: o PPG-7}

O Projeto Resex fez parte do Programa Piloto para a Proteção das Florestas Tropicais do Brasil (PPG-7). O Programa Piloto foi proposto pelo Grupo dos Sete (G-7), em Houston, Texas (EUA), em 1990, aprovado pelo G-7 e pela Comissão Europeia em dezembro de 1991 e oficialmente lançado no Brasil em 1992, durante a Conferência das Nações Unidas para o Meio Ambiente e o Desenvolvimento, a ECO $92^{1}$. Segundo o decreto que o institui, o PPG-7 consistia em um conjunto de projetos integrados do "governo federal e da sociedade civil brasileira" com o 
apoio técnico e financeiro da comunidade financeira internacional, com objetivo de implementar um modelo de desenvolvimento sustentável em florestas tropicais brasileiras (BRASIL, 1992).

O acordo de doação do Fundo Fiduciário da Floresta Tropical e doação da Comissão das Comunidades Europeias foi assinado, entre o Brasil e o BIRD, em 16 de novembro de 1994. O Banco Mundial tornou-se o administrador dos fundos e o governo brasileiro nomeou o Ministério do Meio Ambiente como responsável pela Coordenação do Programa Piloto, tendo como instância de execução o Instituto Brasileiro do Meio Ambiente e dos Recursos Naturais Renováveis (Ibama). O papel intelectual do Banco Mundial é destacado por avaliadores do PPG-7 ao analisarem as articulações deste Programa com o que denomina "política integrada para a Amazônia", assim como seu papel central no planejamento e na execução, no contexto do Programa Piloto, em termos da disseminação mais ampla das lições aprendidas por toda a Amazônia e pelo mundo em geral (IAG, 1996).

Durante sua execução, é explícito o papel desempenhado pelo PPG-7 na definição das políticas para a Amazônia. Por sua dimensão territorial, o volume de recursos disponibilizados e a abrangência de ações, o PPG-7 assumiu um papel importantíssimo na definição dessas políticas, notadamente as ambientais, para a Amazônia e Mata Atlântica, na década de 1990. Vale lembrar que, por meio de suas ações, foram elaborados zoneamentos ecológico-econômicos, estruturados órgãos ambientais nos estados e municípios, assim como, sob sua influência, foram articuladas políticas estaduais de meio ambiente e reconfigurado o quadro institucional ambiental brasileiro. Como nos diz Mello (2006, p. 110),

[...] o maior resultado do PPG-7 é o de contribuir para a reconfiguração das forças geopolíticas no território amazônico, ao fomentar as ligações global-local, e o aprendizado do enfoque ambiental, ao difundir princípios, técnicas e alternativas de sistemas produtivos, e ao desfazer estereótipos técnicos e políticos.

Diante desse panorama de centralidade do PPG7 nas políticas dos estados da Amazônia, cabe-nos problematizar a pergunta feita pelo GTA²/Amigos da Terra, quando o Programa completava dois anos de efetiva execução: “quem está sendo pilotado por este Programa, e para onde?” (GTA, 1997, p. 12).

\section{Projeto Resex: teste e modelo para as Reservas Extrativistas}

No escopo do PPG-7, o Projeto Resex compôs o Subprograma Unidades de Conservação e Manejo de Recursos Naturais, que incluía projetos específicos para Terras Indígenas e a formação de Corredores Ecológicos. O Projeto Resex apresentou como objetivo:

[...] testar em quatro reservas extrativistas da Amazônia brasileira modelos apropriados de gerenciamento econômico, social e ambiental, 'aperfeiçoando os métodos e procedimentos utilizados pelas populações tradicionais' na administração dos recursos naturais renováveis das florestas tropicais, por meio da 'cogestão entre governo e sociedade’ (IBAMA, 2000, p. 77, grifo nosso).

Foram estruturadas atividades que contemplavam as fases de implementação das Reservas Extrativistas, a partir de ações organizadas em cinco componentes básicos:

a) efetivação das Reservas Extrativistas;

b) organização comunitária;

c) melhoria de atividades produtivas;

d) gerenciamento ambiental e

e) gerenciamento e avaliação do Projeto.

Essas ações compreendiam desde regularização fundiária à organização dos processos produtivos, passando pela organização social nas Resex e pelo apoio logístico ao Centro Nacional de Desenvolvimento Sustentado das Populações Tradicionais $(\mathrm{CNPT})^{3}$ em Brasília e nas demais regiões (IBAMA, 1999). Assim, o Projeto Resex tinha a pretensão de ser uma experiência piloto na Amazônia, na qual deveriam se espelhar outras iniciativas.

Dentre as obrigações do governo brasileiro para com o Projeto constam:

a) fornecer ao administrador e, a partir de então, implementar um plano de utilização (o plano de utilização da Resex) 'satisfatório ao administrador', para cada uma das Reservas Extrativistas estipulando, entre outras coisas, as atividades proibidas [...]; b) implementar um plano de desenvolvimento (o plano de desenvolvimento da Resex), 'satisfatório ao administrador', para cada uma das Resex, detalhando as atividades a serem desenvolvidas para o desenvolvimento da Reserva Extrativista e para o manejo de suas reservas naturais e c) dentro de um um ano após a data de vigência, implementar um sistema de monitoramento ambiental, 'satisfatório ao administrador' para monitorar as Reservas Extrativistas e a implementação do projeto (BRASIL, 1994, p. 16, grifo nosso).

Ora, na prática, quando um financiador condiciona o empréstimo a alguns princípios atendidos, ele está definindo a forma de organização do contratante, uma vez que o empréstimo somente será concedido mediante o atendimento de "condicionantes". Assim, o 
Banco (administrador), em última instância, precisaria aprovar os instrumentos de gestão que estavam sendo implementados nas Resex. Não queremos dizer com isso que não há a necessidade de critérios e de regras claras. A questão está fundamentada na forma de definição desses critérios e dessas regras, se eles são elaborados conjuntamente pelas partes envolvidas ou em uma situação de subordinação.

Dois fatos chamam a atenção nos objetivos do Projeto Resex:

a) a auto-gestão antes requerida pelos seringueiros e presente em todos os seus documentos é substituída por cogestão ${ }^{4} \mathrm{e}$

b) a necessidade de aperfeiçoamento do conhecimento das populações residentes nas Reservas Extrativistas, para fins de administração. Nos documentos dos seringueiros, estava claramente exposto o papel do Estado como provedor dos meios necessários para que as decisões sobre o território fossem tomadas por seus moradores, o que incluía definir as bases de sua organização, produção e o ritmo a ser adotado para estas questões (CNS, 1992).

Assim, a ideia original de auto-gestão é subsumida pela cogestão, que em última instância vai assumindo os contornos da parceria público-privado, exaltada na reforma do Estado, através das organizações sociais não estatais. Confere-se um novo significado ao sentido de auto-gestão em consonância com uma ressignificação do papel do Estado. Verificamos, assim, talvez a primeira sinalização do papel que o Projeto Resex ocuparia na redefinição das categorias estruturantes da proposta dos seringueiros.

Em relação às ações de capacitação, existe ainda outra questão. Ao buscar "educar" os moradores das Resex, capacitando-os (instrumentalizandoos) na melhoria do manejo da área e na organização comunitária, é roubado desses sujeitos a possibilidade de "auto-educar-se", formando-se sujeitos de transformação. Nesse caso, entendendo que o processo educativo ocorre socialmente, estamos nos referindo à educação em classe, tendo o trabalho como princípio educativo, e compreendida como um processo, ao mesmo tempo, de humanização. Como nos lembra Lukács (2007), colocamo-nos um falso problema, pois acredita-se que é preciso formar para transformar a realidade, quando, na verdade, formam-se cidadãos transformando-se realidades.

Nessa inflexão no campo da formação, que passa a vir de fora, encomendada, sem problematização com os sujeitos, pautada no conhecimento técnico ajustado aos ditames do mercado e aos comportamentos próprios da sociabilidade burguesa, perdese a oportunidade histórica de, em uma situação concreta, com sujeitos concretos, construírem-se novos cidadãos. Com o olhar voltado para o futuro, perde-se a materialidade do presente como substrato para a construção de uma nova realidade.

\section{A reconfiguração social nas Reservas Extrativistas}

Antes da definição das áreas como Reservas Extrativistas, as instâncias de representação reconhecidas pelas comunidades consistiam no sindicato, em nível local e regional, enquanto o Conselho Nacional dos Seringueiros afirmava-se como interlocutor em nível nacional. Após a implementação do Projeto Resex, novas figuras jurídicas passaram a se impor na região: as Associações das Reservas. No Acre, as Associações dos Moradores da Reserva Extrativista Chico Mendes foram criadas em 1994, em reunião em Assis Brasil (Amoreab), Brasileia (Amoreb) e Xapuri (Amorex $)^{5}$, ao tempo em que a Associação dos Seringueiros e Agricultores da Bacia do Rio Tejo passou a denominar-se como Asareaj, configurando-se na instância representativa da Resex do Alto Juruá.

As associações logo passaram a desempenhar um importante papel na suposta organização dos moradores e na interlocução destes com o Ibama e demais órgãos que se relacionavam com a Resex. Assim como passaram a representar o locus de discussão dos instrumentos de gestão da Resex (plano de utilização e plano de desenvolvimento), sendo consideradas as "cogestoras" da Unidade, responsáveis pela mobilização dos moradores, realização das assembleias e beneficiárias no contrato de concessão de uso.

O recebimento dos recursos do Projeto Resex e a necessidade de realização de convênios para a realização de suas atividades foram determinantes para a criação das Associações. Paula (2003) salienta que "os de baixo", com a chegada de financiamentos a fundo perdido, ajustam suas estratégias às exigências externas ao invés de criar novas estratégias de desenvolvimento. A intenção é demonstrar competência para atrair financiamentos e com isso provar a viabilidade econômica das Reservas Extrativistas.

Apesar do objetivo declarado de atender a uma necessidade/intenção de organização comunitária, visando seu fortalecimento, na prática o esvaziamento do sindicato gerado por essa ação ${ }^{6}$ e a subordinação das associações aos recursos do Projeto Resex (financiamento externo sem garantia de responsabilidade) geraram o enfraquecimento da capacidade de mobilização antes existente, expressa no descrédito nas entidades representativas.

Diferente do processo de enfrentamento que levou à criação dos primeiros sindicatos na região, a criação dessas novas institucionalidades (associações e núcleos de base) teve origem em um projeto com orientação governamental. Concordamos com Brown e Rosendo (2000) quando afirmam que o fortalecimento de organizações locais pode ser incentivado ou financiado por uma instituição externa, desde que 
as populações locais decidam a forma como essa organização funcionará. Os autores atentam ao fato de que esse processo não pode ser imposto externamente ou ser planejado "pelo alto".

Ao tempo em que o "novo sindicalismo" das décadas de 1970/1980, que contribuiu para a conformação do Movimento Seringueiro, contrapôs-se a um sindicalismo de resultados atrelado ao Estado, as novas lideranças que começam a surgir na Resex, assumem seu papel em posição subordinada ao Estado, por dele dependerem não apenas em recursos financeiros como também na definição de sua pauta de discussão. Não se tratava apenas do tipo de organização que os seringueiros deveriam seguir, mas do tipo de atividade que esta organização deveria realizar e a quais recursos estaria submetida. As Associações da Reserva, ao invés de enfrentamento e contestação, foram criadas com sentido de colaboração, em busca de "bem comum", de "melhoria na qualidade de vida" que não mais reside na transformação das relações existentes, e, sim, em uma adaptação às mesmas.

Desvinculando o econômico do político, os seringueiros cediam à abstrata dissociação característica do capitalismo-neoliberalismo ${ }^{7}$. Uma nova interlocução era criada e com ela um novo significado de relação com o Estado. Enquanto o sindicato, na década de 1970, impôs-se como interlocutor a ser considerado, nesse momento, era o Estado que definia com quais interlocutores dialogaria.

A complexidade das novas mediações, e sua influência sobre o Movimento, é exemplificada por Paula (1998) quando destaca a diferença entre as reivindicações dos sindicatos (de longo prazo, estruturantes) e as "conquistas" das associações (mostradas de forma imediata e concreta como caminhões, tratores) como uma das causas de desarticulação das bases sindicais, observadas na década de 1990. Para Rueda (1995), os sindicatos cumpriam uma missão política, enquanto as associações se dedicariam aos "aspectos de melhoria da produção e comercialização”. Assim, consolida-se uma visão dissociada entre as esferas econômica e política.

A responsabilização do Estado, antes tão presente e pautada pelo Movimento, passa a ser substituída pela necessidade de parcerias; a participação dos seringueiros na elaboração de propostas e definição de seus rumos é subsumida por um projeto que já vem definido e que os consome em atividades de implantação, e não de organização, para atender às demandas de um financiador que não necessariamente atende as suas. Uma educação para arte do possível foi desenvolvida com maestria.

Por último, é importante destacar que a criação das associações e sua formalização como modelo de organização requerida para representar os moradores ou beneficiários de uma reserva levou a uma padronização no modelo de estrutura social nas Reser- vas Extrativistas. O que não havia sido previsto na lei que criou as Resex, ou nas diretrizes construídas pelos seringueiros, foi estabelecido como produto do Projeto Resex, sendo incorporado nas regulamentações adotadas pelo CNPT, naturalizando-se, assim, a existência das Associações como instâncias representativas em todas as Resex criadas, independente dos arranjos institucionais já existentes.

\section{Projeto Resex como espaço pedagógico}

As ideias e as opiniões não 'nascem' espontaneamente no cérebro de cada indivíduo: tiveram um centro de formação, de irradiação, de difusão, de persuasão, houve um grupo de homens ou até mesmo uma individualidade que as elaborou e apresentou na forma política da atualidade (GRAMSCI, 2007, p. 82).

A importância do Projeto Resex na definição do esqueleto organizacional que daria suporte às Reservas Extrativistas, tanto no âmbito governamental quanto nas instâncias de representação dos moradores, está diretamente ligada aos recursos disponibilizados pelo Projeto. O montante de recursos financeiros disponível no Projeto e a quantidade de técnicos que estavam a sua disposição fizeram com que as Resex fossem o grande centro de produção ideológica dos conceitos que viriam nelas a ser utilizados.

Não podemos minimizar o papel desempenhado pelo Projeto Resex na organização de todo o "Sistema Reservas Extrativistas", e no próprio funcionamento do $\mathrm{CNPT}^{8}$, que na prática, passou a depender de seus recursos. Vejamos o que diz o relatório do Projeto:

A experiência adquirida na gestão das quatro Reservas Extrativistas tornou possível 'exportar' as seguintes iniciativas bem sucedidas:

- o sistema de fiscais colaboradores foi implantado em outras oito Reservas;

- Treinamentos para a criação dos Núcleos de Base já estão sendo realizados nas Reservas TapajósArapiuns e Médio Juruá;

- O monitoramento ambiental participativo também torna-se realidade em todas as outras Reservas (IBAMA, 1999, p. 26, grifo nosso).

A capacidade educativa do Projeto Resex, como espaço de difusão de conceitos e organização do consenso pode ser compreendida pela sua capacidade de contato nas diversas localidades das Reservas Extrativistas, o que antes era limitado em função dos meios disponíveis. Segundo o relatório final da primeira fase do Projeto, foram realizados 672 eventos de capacitação, em cinco anos, em que eram abor- 
dados assuntos relacionados, desde organização comunitária à melhoria do extrativismo. Além disso, técnicos dos projetos (extensionistas sem necessariamente uma formação crítica) estavam presentes em todas as áreas, seja diretamente nas comunidades, seja na assessoria às associações criadas. Ademais, o entrelaçamento das pessoas que circulavam em diferentes espaços e tinham, assim, diferentes localizações demarca o papel dos consultores na difusão dos conceitos que circulavam nesse período, entre os mais diferentes grupos, seja no âmbito governamental ou não governamental.

Para nós, está claro que mais do que testar, o Projeto Resex desempenhou um papel importante na organização das relações sociais e de produção nos períodos seguintes. Da mesma forma que o papel do Estado é ideologicamente apresentado como neutro, retirando-lhe o papel de organizador das relações, o mesmo se faz com os projetos como novas estratégias de educar o consenso. No lugar da polícia, estratégia repressora do Estado para adesão ao seu projeto de desenvolvimento, optou-se pela estratégia da adesão por consenso, proporcionada pelas ideologias difundidas por meio dos projetos. Novas versões de organização comunitária, papel do Estado, responsabilidade conjunta, eram assim construídas de forma a serem não apenas difundidas, mas defendidas por quem um dia as criticou. Acreditamos que o PPG-7, e de forma mais específica o Projeto Resex, representou um ótimo exemplo da estratégia relatada por Goldman (2001) ${ }^{9}$ :

$\mathrm{O}$ acesso de capitais nacionais e internacionais a zonas remotas e ricas em recursos e força de trabalho vem sendo obtido através de experimentações sociais e do expansionismo do Estado em nome do 'fazer as áreas comuns funcionarem'. Na maioria dos casos, as agências governamentais de desenvolvimento do Terceiro Mundo tornam-se guardiães de um volume relativamente grande de capitais estrangeiros, especificamente direcionados a reestruturar relações sociais-naturais em áreas 'subdesenvolvidas', para que os projetos, e o próprio Estado, possam criar raízes e as relações capitalistas possam frutificar (GOLDMAN, 2001, p. 70, grifos do autor).

O Banco Mundial cumpria na Amazônia e, especificamente, nas Reservas Extrativistas seu papel intelectual:

Em outras palavras, a partir de 1992-93, o Banco respondeu às críticas ambientalistas lançando-se poderosamente no campo ambiental como ator político, financeiro e intelectual. O corolário dessa contraofensiva foi a cooptação e ressignificação do ambientalismo [...] Afirmando que o 'desenvol- vimento sustentável' poderia não ocorrer sem o uso econômico eficiente do meio ambiente, o Banco impulsionou a transformação das regras e instituições ambientais organizadas segundo princípios não capitalistas numa direção condizente com as políticas de livre mercado (PEREIRA, 2009, p. 217 218, grifo do autor).

Assim como Pereira (2009) demonstrou que o Banco Mundial atuou como ator político e intelectual na difusão de ideias em prol do desenvolvimento capitalista, por intermédio de condicionantes de projetos e financiamentos que vão definindo as atividades necessárias nos diferentes países, temos razões para afirmar que, no caso das Reservas Extrativistas, o Projeto Resex foi o principal instrumento para esta finalidade, atuando, por intermédio dos atores envolvidos, na definição, organização e difusão de conceitos que definiriam o "vir a ser" dessas unidades.

O Projeto Resex ajudou a consolidar na sociedade política (CNPT) e na sociedade civil (Associações e CNS) os elementos de uma nova sociabilidade, funcionais (e determinantes) à reforma do Estado em curso. Se as Reservas Extrativistas representaram uma estratégia contra-hegemônica, uma vez que claramente se posicionavam em oposição aos pilares da sociedade capitalista (direito de propriedade individual e autonomia burguesa), o projeto que fundamentou sua implementação e consolidação atendia perfeitamente aos ideários dessa sociedade, ressignificando elementos fundamentais para a continuidade da luta dos seringueiros e individualizando-os, na medida em que os deslocava da luta emancipatória da classe trabalhadora.

Valendo-nos da análise de Dagnino (2004), quando destaca a confluência perversa ${ }^{10}$ entre um projeto político democratizante, participativo, e o projeto neoliberal, através de três dimensões (sociedade civil, participação e cidadania), observamos, através do relatório final do Projeto (IBAMA, 2000), a identificação, no discurso oficial do governo brasileiro, argumentos que reiteram a análise aqui desenvolvida.

Ao focar na autoestima do seringueiro, abstraindo das relações de poder ainda existentes nos seringais, há uma inversão das condições de produção e reprodução social para a questão individual/moral, imputando ao indivíduo e à sua disposição em colaborar com o sucesso das Reservas Extrativistas. Há uma ressignificação da noção de participação, levando-a para o âmbito moral/privado/individualista. Com isso, os espaços públicos, anteriormente criados e necessários para o fortalecimento dos seringueiros como sujeitos revolucionários, são subsumidos nos espaços de participação para a gestão de uma Unidade de Conservação, favorecendo-se a participação institucionalizada no interior dos aparelhos estatais, sem destruir os marcos das relações capitalistas. 
A noção de cidadania é reduzida ora aos direitos formais (carteira de identidade, $\mathrm{CPF}$ ), ora aos direitos de inserção no mercado (aquisição de créditos, participação em projetos), retirando-lhe o caráter de luta por direitos ainda não existentes, no sentido de reconhecimento às especificidades deste grupo social na universalidade da luta dos trabalhadores por justiça social. Ao focalizar no sujeito individual e seus direitos, tira-se de foco a construção do sujeito social, coletivo, na disputa por uma construção ético-política nas relações sociais, não mais restritas apenas à relação com o Estado.

Assumir o mercado como parâmetro de avaliação para a cidadania significa impor a este o verdadeiro espaço de realização do sujeito, como requer o liberalismo. A questão não mais se trata de um modelo de sociedade, por princípio excludente, que deixa de fora os extrativistas. Trata-se da falta de condições desses extrativistas competirem nesse mercado, questões que podem ser resolvidas pela capacitação e agregação de valor. Ou seja: sem alterar os fundamentos do sistema. Trata-se de inserção no mercado e não de contraposição a este. Aproveitamo-nos das palavras de Lima e Martins (2005, p. 65, grifos do autor) que tão bem se aplica a essa situação:

[...] temas antigos, como 'cidadania', 'igualdade', 'participação', 'democracia', e novos, como 'empreendedorismo', 'voluntariado', 'responsabilidade', dentre tantos outros, são tratados sob uma abordagem pedagógica que os distancia do conflitivo e antagônico processo de construção social que os define. Trata-se de uma ação orientada por uma concepção pedagógica que procura criar novas ancoragens teóricas e simbólicas responsáveis por estabelecer mediações entre sujeito e realidade social em uma perspectiva de conservação das relações sociais.

\section{Considerações finais}

Com o relato da pesquisa feita, procuramos contribuir para a compreensão mais aprofundada do significado do Projeto Resex para os objetivos inicialmente colocados para as Reservas Extrativistas. Independentemente de o Projeto ter auxiliado na implementação das Resex, a pergunta que tentamos responder foi: o processo de implementação que teve andamento com apoio financeiro e pedagógico do Projeto Resex correspondeu às demandas anteriormente expostas pelos seringueiros ou cumpriu o papel de inseri-los subordinadamente no sistema?

A implementação do Projeto Resex cumpriu um considerável papel pedagógico por meio das associações e dos técnicos a elas vinculados, no convencimento da população das reservas sobre a importância de voltar-se às suas necessidades imediatas e locais, em detrimento de uma visão coletiva e de longo prazo. Assim, dissociando o econômico do político, negava-se o Movimento Seringueiro em sua capacidade de articulação e ampliação da luta contra subalternização e subordinação da classe trabalhadora, em nome de uma redução limitada a interesses imediatos.

Podemos entender a parca dotação de recursos orçamentários para as Resex, a falta de articulação de políticas públicas que lhes dessem sustentação nas diferentes áreas (educação, saúde, produção, transporte) e a opção por financiamento através de projetos e parcerias, como parte de um projeto maior de sociabilidade em que não havia espaço para iniciativas que buscavam o protagonismo dos grupos subalternos, como é o caso da proposta que originou as Reservas Extrativistas.

A ausência de políticas não deve significar "ausência do Estado", ao contrário, significa uma forma de atuação, uma intencionalidade direcionada à obtenção e consolidação do consenso em favor da hegemonia neoliberal. Diferente do apregoado, na década de 1990 o Estado não foi ausente das Resex. Ao contrário, fez-se presente, de maneira distinta da planejada pelos seringueiros, mas de acordo com os princípios contidos na consolidação de uma sociedade capitalista.

\section{Referências}

AZEVEDO, L. A. M. de. O projeto Reservas Extrativistas e as políticas públicas para as populações extrativistas da Amazônia, o caso do estado do Acre. 2003. 106 f. Dissertação (Mestrado em Desenvolvimento Sustentável, Política e Gestão Ambiental) - Centro de Desenvolvimento Sustentável, Universidade de Brasília, Brasília, DF, 2003. 
BRASIL. Decreto $n$. 98.897, de 30 de janeiro de 1990. Dispõe sobre as reservas extrativistas e dá outras providências. Disponível em: <http://www.planalto.gov.br/ccivil 03/decreto/Antigos/ D98897.htm>. Acesso em: 12 jul. 2009.

. Decreto n. 563, de 5 de junho de 1992. Institui o Programa Piloto para a Proteção das Florestas Tropicais do Brasil e Cria a Comissão de Coordenação. Disponível em: <http://www6. senado.gov.br/legislacao/ListaPublicacoes.action? id=225696>. Acesso em: 7 jul. 2009.

. Acordo de doação do Fundo Fiduciário da Floresta Tropical e doação do CCE - Projeto de Reservas Extrativistas entre a República Federativa do Brasil e o Banco Internacional para a Reconstrução e o Desenvolvimento. Brasília, DF, 1994.

Lei n. 9.985, de 18 de julho de 2000. Sistema Nacional de Unidades de Conservação da Natureza-SNUC. Diário Oficial da União, Brasília, seção 1, p. 1, 19 jul. 2000.

BROWN, K.; ROSENDO, S. Enviromentalists, Rubber Tappers and Empowerment: The Politics and Economics of Extractive Reserves. Development and Change, Oxford, v. 31, p. 201-227, jan. 2000.

CNS - Conselho Nacional dos Seringueiros. Encontro Nacional dos Seringueiros III, de 26 a 29 de março de 1992, Rio Branco, Acre. Disponível em: 〈http://www.cnsnet.org.br/>. Acesso em: 6 jul. 2007.

CUNHA, C. C. Reservas extrativistas: institucionalização e implementação no Estado brasileiro dos anos 1990. 2010. $308 \mathrm{f}$. Tese (Doutorado em Psicossociologia de Comunidades e Ecologia Social) - Instituto de Psicologia, Universidade Federal do Rio de Janeiro, Rio de Janeiro, 2010.

DAGNINO, E. Sociedade civil, participação e cidadania: de que estamos falando? In: MATO, D. (Coord.) Políticas de ciudadanía y sociedad civil em tiempos de globalización. Caracas: Faces, 2004, p. 95-110.

GOLDMAN, M. Inventando os comuns: teorias e práticas do profissional em bens comuns. In: DIEGUES, A. C. S.; MOREIRA, A. de C. C. (Org.) Espaços e recursos naturais de uso comum. São Paulo: Núcleo de Apoio à Pesquisa sobre Populações Humanas e Áreas Úmidas Brasileiras, USP, 2001, p. 43-78.

GRAMSCI, A. Cadernos do cárcere. Tradução de Carlos Nelson Coutinho, Luiz Sérgio Henrique e Marco Aurélio Nogueira. Rio de Janeiro: Civilização Brasileira, 2007. (v. 3).

GTA - Grupo de Trabalho Amazônico Amigos da Terra. Políticas públicas para a Amazônia: rumos, tendências e propostas. Documento apresentado à reunião dos participantes do Programa Piloto para a Proteção das Florestas Tropicais do Brasil, Manaus, 27-30 out. 1997. Versão Preliminar.

IAG - Grupo de Assessoria Internacional. Relatório, VII reunião, realizada em Brasília, no período de 2 a 6 de dez. de 1996.
Programa Piloto para a Proteção das Florestas Tropicais do Brasil. Brasília, DF, 1996.

IBAMA. Projeto Reservas Extrativistas: um futuro sustentável para a Amazônia. Brasília, DF, 1999. Cartilha.

Projeto Reservas Extrativistas: Relatório Final da $1^{\text {a }}$ fase - 1995-1999. Brasília, DF, 2000.

LÉNA, P. As políticas de desenvolvimento sustentável para a Amazônia: problemas e contradições. Boletim Rede Amazônia, Rio de Janeiro, ano 1, n. 01, p. 9-21, 2002.

LIMA, K. R. de S.; MARTINS, A. S. Pressupostos, princípios e estratégias. In: NEVES, L. M. W. (Org.). A nova pedagogia da hegemonia: estratégias do capital para educar o consenso. São Paulo: Xamã, 2005, p. 41-67.

LUKÁCS, G. O jovem Marx e outros escritos de filosofia. Organização, apresentação e tradução de Carlos Nelson Coutinho e José Paulo Netto. Rio de Janeiro: Ed. da UFRJ, 2007. (Pensamento Crítico, v. 9).

MELLO, N. A. de. Políticas territoriais na Amazônia. São Paulo: Annablume, 2006.

NEVES, L. M. W.; SANT'ANNA, R. Gramsci, o Estado educador e a nova pedagogia da hegemonia. In: NEVES, L. M. W. (Org.). A nova pedagogia da hegemonia: estratégias do capital para educar o consenso. São Paulo: Xamã, 2005, p. 21-39.

PAULA, E. A. de. (Coord.). A conquista da terra nas florestas do Acre. In: MEDEIROS, L. S. de; LEITE, S. P. (Coord.). Impactos regionais dos assentamentos rurais: dimensões econômicas, políticas e sociais. Relatório convênio FINEO/ CPDA/UFRRJ, 1998.

Estado e desenvolvimento insustentável na Amazônia Ocidental: dos missionários do progresso aos mercadores da natureza. 2003. 217f. Tese (Doutorado em Desenvolvimento e Agricultura) - Universidade Federal Rural do Rio de Janeiro, Rio de Janeiro, 2003.

PEREIRA, J. M. M. O Banco Mundial como ator político, intelectual e financeiro (1944-2008). 2009. 382 f. Tese (Doutorado em História) - Instituto de Ciências Humanas e Filosofia, Universidade Federal Fluminense, Niterói, 2009.

PORTO-GONÇALVES, C. W. Natureza e sociedade: elementos para uma ética da sustentabilidade. In: QUINTAS, J. S. (Org.). Pensando e praticando a educação ambiental na gestão do meio ambiente. Brasília: Ibama, 2000, p. 49-76. (Coleção meio ambiente, n. 3).

RUEDA, R. P. Organização social das populações extrativistas. In: MURRIETA, J. R.; RUEDA, R. P. Reservas Extrativistas. Cambridge: UICN; Brasília: CNPT/Ibama, 1995, p. 13-17. 
WOOD, E. M. Democracia contra capitalismo: a renovação do materialismo histórico. Tradução de Paulo Cezar Castanheiras. São Paulo: Boitempo, 2003.

. Estado, democracia y globalizacíón. In: BORON, A. A.; AMADEO, J.; GONZALEZ, S. (Comp.). La teoría marxista hoy - problemas y perpectivas. Buenos Aires: Clacso, 2006, p. 395-407.

\section{Notas}

1 Informações disponíveis em: 〈http://www.mma.gov.br/ppg7/>. Acesso em: 29 jul. 2009.

2 Durante a vigência do Projeto Resex, o Grupo de Trabalho Amazônico (GTA) teve papel protagônico na representação das comunidades em diversos fóruns, chegando a assinar conjuntamente com o Conselho Nacional dos Seringueiros (CNS) alguns documentos. A estratégia de fórum de ONGs em função de Projetos de cooperação já havia acontecido em outras ocasiões, como foi o caso da criação, em 1991, do Fórum de ONGs de Rondônia para acompanhamento do Planafloro (BROWN; ROSENDO, 2000).

3 Setor do Ibama criado em 1992 para gestão das Reservas Extrativistas. Em 2009, já incorporado ao Instituto Chico Mendes de Conservação da Biodiversidade passa a existir como Centro de Pesquisa, com denominação de Centro Nacional de Pesquisa e Conservação da Sociobiodiversidade Associada aos Povos e Comunidades Tradicionais.

4 Esta inflexão empresta sentido a modificações inseridas posteriormente, com a inclusão das Resex no Sistema Nacional de Unidades de Conservação, Lei n. 9.985 (BRASIL, 2000). Com esta lei, torna-se obrigatória a existência de um Conselho Deliberativo, como instância gestora da Resex. O Conselho deve ser representativo das instituições que se relacionam com a Unidade, ampliando-se a participação de diferentes entes nas tomadas de decisão. Isto para as outras categorias de unidades de conservação poderia significar um aumento no controle social, mas para as reservas extrativistas e sua estrutura de gestão anteriormente proposta, pode representar a diluição de poder dos extrativistas na gestão de seu território.

5 Em 1997, por exigência dos bancos para fins de financiamento, as associações passaram a acrescentar a palavra "produtores" em sua denominação, passando a ser denominadas: Associação dos Moradores e Produtores da Reserva Extrativista Chico Mendes, respectivamente Amopreab, Amopreb e Amoprex.

6 É válido ressaltar o processo de desmobilização pelo qual passavam os sindicatos no cenário nacional, em função da precarização das relações de trabalho e da desregulamentação dos direitos trabalhistas, característicos da década de 1990, que provocou alterações também por dentro do movimento sindical.
7 Para Wood (2003), uma das principais consequências de concentrar a luta de classes no plano econômico, dissociado do político, é o fato de não afetar a relação entre os trabalhadores e os donos dos meios de produção, domesticando as lutas de classes. Em trabalho posterior a autora complementa: "[...] agora é possível ter um novo tipo de democracia que está confinada a uma esfera puramente política e judicial - aquela que alguns denominam democracia formal - sem destruir os cimentos do poder de classe" (WOOD, 2006, p. 401, tradução nossa).

8 Para entender a importância atribuída ao arcabouço institucional, no Projeto Resex, basta-nos verificar o montante de recursos destinados a ações diretamente ligados ao CNPT, CNS e Associações, denominadas no relatório como: a) criação e consolidação de associações, b) fortalecimento institucional das associações e c) assistência técnica/apoio CNPT/CNS. Juntas, essas ações receberam recursos na ordem de US\$3.282.886, representando 41\% do total de recursos aplicados no período 1995/1999 (IBAMA, 1999).

9 Neste artigo, Michael Goldman dedica-se a desvendar os sentidos impregnados nas ações e falas dos profissionais que atuam junto aos recursos de propriedade comum, destacando o papel desempenhado pelos especialistas em desenvolvimento e gerentes de projeto do Banco Mundial na difusão de conceitos que visam uma uniformização dos comuns, baseados em relação de poder fundado no conhecimento.

10 Dagnino (2004,p. 95, 97,99) analisa que existiu, na década de 1990, uma "confluência perversa entre um projeto político democratizante, participativo, e o projeto neoliberal, que marcaria [...] o cenário da luta pelo aprofundamento da democracia na sociedade brasileira". A autora destaca a ocorrência de uma ressignificação de conceitos caros a um projeto democratizante, que foram esvaziados de seu sentido contestatório, argumentando que a perversidade reside no fato de que "apontando para direções opostas e até antagônicas, ambos os projetos requerem uma sociedade civil ativa e propositiva". Comisso, ocorre um "obscurecimento de distinções e divergências, por meio de um vocabulário comum e de procedimentos e mecanismos institucionais que guardam uma similaridade significativa". 


\section{Cláudia Conceição Cunha}

cccunha@hotmail.com

Doutora em Psicossociologia de Comunidade e Ecologia Social pela Universidade Federal do Rio de Janeiro (UFRJ)

Analista ambiental do Centro Nacional de Pesquisa e Conservação da Sociobiodiversidade Associada aos Povos e Comunidades Tradicionais (CNPT), Instituto Chico Mendes de Conservação da Biodiversidade (ICMBio)

\section{Carlos Frederico B. Loureiro}

floureiro@openlink.com.br

Doutor em Serviço Social pela UFRJ

Professor dos Programas de Pós-Graduação em Educação (PPGE) e em Psicossociologia de Comunidades e Ecologia Social na UFRJ

Instituto Chico Mendes de Conservação da Biodiversidade (ICMBio)

Avenida Antônio da Rocha Viana, n. 1586

Bairro Vila Ivonete

Rio Branco - Acre

CEP: 69908-560

\section{PPGE - UFRJ}

Av. Pasteur, $250 \mathrm{~F}$

Praia Vermelha

Rio de Janeiro - Rio de Janeiro

CEP: $22290-240$ 